\title{
A Justificação do Inconsciente e a Aposta de Pascal
}

\author{
Eduardo Ramalho Rotstein* \\ Universidade Federal do Rio de Janeiro, Rio de Janeiro, Brasil
}

\begin{abstract}
RESUMO
O presente artigo busca apreender a importância da justificação freudiana do inconsciente para a definição do estatuto da Psicanálise. Um exame do objeto, da motivação e dos momentos argumentativos dessa justificação evidencia que a prova da existência do inconsciente intentada nela não se conforma ao modelo de demonstração empírica perseguido por Freud. Trata-se, antes, de uma demonstração pragmática, procedimento semelhante ao utilizado por Pascal na sua aposta em favor da existência de Deus. Contudo, essa similaridade não implica que a Psicanálise seja um saber especulativo: a admissão do inconsciente, embora não inteiramente justificável empiricamente, mostra-se como a condição da experiência analítica.
\end{abstract}

Palavras-chave: inconsciente; psicanálise; aposta de Pascal; metapsicologia.

\section{ABSTRACT}

\section{The justification of the unconscious and Pascal's wager}

The present article seeks to apprehend the importance of Freud's justification of the unconscious for defining the status of psychoanalysis. Examining subject, motivation and argumentative steps of this justification, reveals that the intended proof of the existence of the unconscious doesn't conform itself to the model of empirical demonstration pursued by Freud. His proceeding is rather a pragmatic demonstration, similar to the one used by Pascal in his wager in favour of God's existence. However, this similarity doesn't mean that psychoanalysis is equal to speculative knowledge: the admission of the unconscious, although empirically not entirely justifiable, reveals itself as the condition of analytical experience.

Keywords: unconscious, psychoanalysis, Pascal's wager, metapsychology.

Passados mais de cem anos desde seu surgimento, a Psicanálise permanece um assunto de intensa discussão não apenas entre os seus adeptos como também entre psicólogos em geral e pesquisadores atuantes em outras áreas. Não surpreende que a pergunta, constantemente recolocada, acerca de seus fundamentos e relações com outros saberes leve, não raro, ao tema do inconsciente. O conceito de inconsciente é fundamental para a Psicanálise. Ele tem papel decisivo em sua delimitação como "psicologia profunda" diante de outras investigações e práticas psicológicas, fornecendo-lhes ao mesmo tempo valorosas contribuições no estudo de fenômenos como o sonho e os sintomas psicopatológicos.

Contudo, é justamente esse conceito que atrai grande parte dos questionamentos dirigidos à Psicaná- lise. Esta nunca se adequou inteiramente ao modelo de investigação empírica - hegemônico à época de sua formulação e ainda vigente na atualidade - pelo fato de seu objeto, uma atividade psíquica não percebida pelo indivíduo, furtar-se à observação e à experiência direta. Foi o próprio inventor da "psicologia que se estende para além da consciência", antes que seus críticos confessos, o primeiro a reconhecer a presença da especulação em seu interior, nomeando-a "Metapsicologia", neologismo declaradamente inspirado em "Metafísica" (Freud, 1898/1986).

Entre os trabalhos mais substanciais dedicados à Metapsicologia, desde os filiados à escola francesa de crítica à Psicanálise (Cavé, 1945; Dalbiez, 1947; Polizter, 1928/1974) até os de comentadores brasileiros (Birman, 1994; Garcia-Roza, 1991), passando pelos

*Endereço para correspondência: Eduardo Ramalho Rotstein - eduardorotstein@ gmail.com 
pós-freudianos anglo-saxônicos (Gill, 1976; Holt, 1989), aquele de Assoun, intitulado Metapsicologia Freudiana (1996), é seguramente um dos mais instrutivos a seu respeito, pois esclarece a problemática da especulação psicanalítica a partir do inconsciente. Assoun explica que Freud nunca abandonou a pretensão de estruturar uma investigação cientificamente legitimada do inconsciente; todavia, como esse objeto é sui generis, encontrando-se, por definição, fora dos limites aceitos de conhecimento, o psicanalista só pôde conquistá-lo à racionalidade científica sob a condição de modificá-la. Daí a necessidade de se formular a Metapsicologia, teoria que encerra "dispositivos de saber" incompatíveis com o modelo empírico de investigação endossado em larga medida pelo próprio Freud.

Desse modo, não surpreende que a problemática acerca do estatuto da Psicanálise surge com toda nitidez no texto $O$ inconsciente (1915c/1975), em especial, na seção primeira, intitulada "A justificação do inconsciente" (Die Rechtfertigung des Unbewußten). Essa justificação é, malgrado a escassez de comentários a seu respeito, um dos empreendimentos teóricos mais importantes registrados na obra de Freud, quiçá em toda a literatura psicanalítica; pois, dando-se por tarefa assegurar o direito à suposição do inconsciente, tal justificação revela a tentativa de conformar a investigação do mesmo a certo modelo epistemológico, a dificuldade de se fazê-lo e, principalmente, a peculiaridade dos procedimentos empregados nessa investigação.

Percebe-se, no entanto, que os escassos trabalhos sobre a Justificação realizados até o presente momento (Caropreso \& Simanke, 2008; Wakefild, 1992), embora apresentem satisfatoriamente os passos da demonstração freudiana, preocupam-se em mostrar seu acordo ao padrão metodológico adotado na pesquisa científica atual, pouco se detendo nos aspectos que divergem desse padrão. $\mathrm{O}$ principal deles reside na semelhança estrutural que essa demonstração mantém com o célebre argumento forjado por Pascal em favor da existência de Deus.

O descobrimento dessa notável semelhança não implica, porém, adotar a posição contrária à dos mencionados trabalhos, isto é, classificar resoluta e definitivamente a Psicanálise como especulação teológica ao invés de ciência. Também nesse caso, perder-se-ia de vista o que há de próprio nos aspectos da justificação do inconsciente até agora pouco examinados. $\mathrm{O}$ presente artigo coloca-se a tarefa, antes, de apreender a peculiaridade do procedimento em jogo nessa justificação e o significado deste procedimento para a definição da Psicanálise. Tendo-se em vista esse objetivo, convém elucidar, recorrendo oportunamente a outras fontes textuais relevantes, o objeto dessa justificação, a motivação que a anima e os seus momentos argumentativos.

\section{O Objeto da Justificação}

É certo que a admissão do conceito em questão, por seu papel fundamental e distintivo, coincide com a própria fundação da psicanálise. Já em Estudos sobre a histeria (Freud, 1893/1987), figura impresso o substantivo "inconsciente", e pode-se afirmar que no Projeto de uma psicologia (Freud, 1895/1987), mesmo não mencionado, o conceito está em pleno uso, uma vez que aí são descritos processos (sediados no sistema $\psi)$ que ocorrem antes de serem percebidos ou sequer alcançam a percepção. Todavia, o inconsciente é tematizado como conceito fundamental e recebe uma tentativa de justificação apenas nos relativamente tardios Algumas notas sobre o conceito de inconsciente na Psicanálise (1912/1975) e $O$ inconsciente (1915c/1975). Ambos imbuem-se das tarefas mencionadas; mas enquanto o texto de 1915 apresenta uma elaboração mais detida da justificação do inconsciente, o de 1912, assim indica seu título, enfoca o esclarecimento do conceito em apreço. Este último oferece-se, assim, como natural ponto de partida para o exame do objeto da justificação. O inconsciente, o que é isso?

Nota-se que o conceito é polissêmico. $\mathrm{O}$ inconsciente se diz de várias maneiras. É possível, contudo, fazer esses sentidos convergirem para uma única elucidação. "Inconsciente" possui um sentido descritivo enquanto designa uma qualidade de algo psíquico (uma representação, por exemplo) que não aparece integralmente ao sentido interno, isto é, à percepção que alguém tem dos próprios estados psíquicos: "Uma representação inconsciente é, assim, de tipo tal que nós não notamos [bemerken]..." (Freud, 1912/1975, p. 29).

Um outro sentido de "inconsciente" é indicado por Freud através do adjetivo "wirksam" (Freud, 1912/1975, p. 30-31). Esse termo, derivado do verbo "wirken", que significa provocar (sobre alguém ou algo) um efeito ou uma mudança de estado, qualifica algo que é produtivo, efetivo ou poderoso. $\mathrm{O}$ inconsciente, como algo efetivo, remete à ideia de que as representações não percebidas são capazes de produzir efeitos sobre a vida consciente, convertendo-se, inclu- 
sive, em ação (Handlung). Por isso, esse sentido é chamado "dinâmico".

O terceiro sentido de "inconsciente" está estreitamente ligado ao dinâmico. Uma vez que toda causalidade pressupõe uma lei segundo a qual estão conectadas entre si causas e efeitos, o inconsciente, na medida em que é efetivo, deixa-se também compreender como uma atividade psíquica sistemática, ou seja, como uma fase necessária, regulada por leis específicas, dos processos que condicionam as ocorrências psíquicas. Trata-se do sentido substantivo do termo, chamado "sistemático" (Freud, 1912/1975). Combinados os sentidos descritivo, dinâmico e sistemático, ganhamos, pois, um esclarecimento básico do inconsciente: atividade psíquica dotada de legislação própria que é despercebida ou percebida a não ser por seus efeitos na consciência.

\section{Por que uma Justificação do Inconsciente?}

Este é, pois, o objeto da justificação empreendida na seção primeira de $O$ inconsciente. Mas por que realizar essa justificação? Seu motivo, ainda que não expressamente declarado, deixa-se apreender sob a consideração do contexto em que foi escrito o artigo. Sabe-se que este deveria integrar, junto com Pulsão $e$ destinos da Pulsão (1915a/1975), O recalque (1915b/1975), Complemento metapsicológico à teoria dos Sonhos (1917/1975) e outros, inacabados, uma única obra de preparação à Metapsicologia, mas o projeto foi abortado por Freud, que se viu na impossibilidade de conferir tratamento sistemático ao material. De qualquer forma, os artigos mencionados formam uma série, a dos "escritos metapsicológicos", cuja unidade é dada pelos pontos de vista assumidos neles e pelo objetivo comum de esclarecimento e aprofundamento das suposições teóricas da Psicanálise (Freud, 1917/1975). A coerência desses escritos autoriza, portanto, a relacionar entre si algumas de suas afirmações como se participassem de um único texto, mesmo que as conexões entre elas restem por vezes veladas.

A motivação que anima a justificação do inconsciente deixa-se iluminar, primeiramente, pelo parágrafo inicial de Pulsões, que contém uma descrição geral do processo de formação de conceitos fundamentais numa ciência. Nenhuma investigação científica parte de definições acerca de seus objetos, isto é, de conceitos largamente determinados dos mesmos, mas da descrição de fenômenos e de sua elaboração mediante agrupamento, ordenação e conexão. No entanto, a elaboração e até mesmo a descrição do material empírico não podem prescindir do auxílio de "ideias abstratas" (abstrakte Ideen), cujo estatuto é intrigante. Elas não têm seu escasso conteúdo determinado a partir do material empírico; antes, impõem a este certa organização. Por outro lado, a sua escolha das ideias abstratas não é arbitrária porque seu conteúdo mantém relações significativas com o material empírico, embora estas ainda não sejam comprovadas, apenas "adivinhadas" (erraten). É, então, após uma pesquisa detalhada da região fenomênica delimitada com ajuda de tais ideias, que se apreendem os conceitos fundamentais de uma ciência e se os alteram progressivamente de modo a torná-los úteis e livres de contradição. Mesmo que disso resultem definições, essas nunca deixarão de ser provisórias, pois as novas experiências obrigam a uma constante renegociação de seu conteúdo: tanto o abandono, quanto o acréscimo de determinações (Freud, 1915a/1975).

Essa descrição não deixa dúvidas quanto ao modelo de ciência em jogo, bem como à concepção de experiência e ao papel que lhe é reservado no conhecimento. Os conceitos são estabelecidos, isto é, preenchidos com determinações, a partir de material empírico: a investigação científica tem na experiência o seu método; apenas com a experiência inicia-se o conhecimento. Por sua vez, a experiência não consiste na mera recepção sensível, mas na organização do material assim dado segundo ideias que, elas próprias, não procedem de tal material, embora a sua escolha dependa da suposição de que possuam alguma relação com este.

O modelo é muito semelhante ao dominante no contexto intelectual da época, ao qual o pensamento freudiano não é, em absoluto, indiferente. Sabidamente, Freud apropria-se de certas teses e conceitos em voga, empregando-os na constituição de uma rudimentar teoria do conhecimento à luz da qual são descritas e avaliadas ciência, Psicanálise e outras construções de pensamento. Essa autêntica "epistemologia freudiana", no dizer de Assoun (1983), aceita a tese então hegemônica de que o único conhecimento legítimo é o científico, e de que este não pode ser obtido sem a participação da experiência.

O sentido específico reservado à 'experiência' na passagem supracitada de Pulsões citada acima mostra-se, aliás, notadamente afim ao sentido atribuído ao termo por Claude Bernard, eminente pesquisador do século XIX que sistematizou os princípios metodológicos da Medicina Científica a partir de experimentos em Fisiologia e Patologia. Na obra canônica Introdução ao estudo da Medicina Experimental, Bernard 
(1865/1966) afirma que a investigação científica repousa sobre experiência, entendendo por isso não a mera constatação de fenômenos, mas a atividade intelectual que busca o conhecimento a respeito das coisas através de uma determinada ordenação dos fenômenos e dos fatos. Assim, no princípio de toda investigação científica se encontrariam conexões ainda não verificadas empiricamente, como hipóteses particulares, formuladas com base em observações anteriores e passíveis de confirmação por novas, e, mesmo, de conexões inverificáveis, como a suposição geral de causalidade entre fenômenos.

No entanto, a ênfase posta por Freud sobre a condição não empírica da investigação científica, nomeadamente, a menção a "ideias abstratas" faltava em sua obra até o parágrafo inicial de Pulsões e não torna a repetir-se em sua consideração epistemológica posterior mais relevante, durante a preleção Sobre uma Weltanschauung (Freud, 1933/1987). Essa ênfase inédita deve-se provavelmente ao assunto tratado pelos escritos metapsicológicos, em especial ao tema do inconsciente. É notável que, enquanto em Pulsões e $O$ recalque são apresentadas quase de imediato as determinações dos conceitos homônimos, em $O$ inconsciente a exposição do conceito em questão é precedida pela discussão em torno do direito de admiti-lo. Tudo indica que o conceito de inconsciente, antes de estabelecer-se como tal, fosse a "ideia abstrata" na qual a investigação psicanalítica se baseia para a circunscrição e a elaboração de seus fenômenos. Se assim for, então a justificação do inconsciente pretende demonstrar, basicamente, que a "ideia" de inconsciente, embora não originada no âmbito fenomênico, não é uma invenção; que essa ideia se relaciona com o empírico do mesmo modo que os conceitos fundamentais de outras ciências. Qual o procedimento, pois, para se comprovar o valor científico da ideia em causa?

\section{Os Momentos Argumentativos}

Na seção inicial de $O$ inconsciente Freud dialoga com uma espécie de opositor imaginário. Este alega ser impossível que algo de natureza anímica, por exemplo, uma representação nossa, possa, ao mesmo tempo, ser inconsciente, isto é, não ser percebido por nós. Seu pressuposto é o de que o consciente recobre toda a extensão do anímico, de modo que se há ocorrências que não são conscientes, então essas não podem ser de natureza anímica. É em resposta a esse objetor que Freud procede à sua justificação do inconsciente.
As suspeitas em torno da ideia de inconsciente seriam dissipadas com a demonstração de que se tem o direito de supor a existência (Existenz) de uma atividade psíquica despercebida, demonstração tanto mais contundente se acompanhada da prova efetiva dessa existência. Em suma: para se justificar a adoção da ideia de inconsciente demanda-se a demonstração do direito à suposição de sua existência e, em última instância, a comprovação dessa existência ${ }^{1}$.

A seção inicia com uma especificação de seu objetivo; ela pretende mostrar que a suposição da existência do inconsciente é necessária e legítima. Embora não se esclareça no que consiste cada uma dessas qualidades e o que as distingue entre si, conclui-se, pela leitura do texto, que a suposição é necessária quando, uma vez adotadas certas premissas, é-se forçado a admiti-la, ao passo que é legítima, se essa suposição se assemelha de tal modo a outras comumente aceitas, que não se poderia recusá-la sem ao mesmo tempo pôr em questão as consolidadas pelo hábito.

\section{A Legitimidade da Suposição do Inconsciente}

Freud afirma que a suposição do inconsciente não se desvia nenhum passo do modo de pensar habitual, tido por correto. A consciência transmite a cada um o conhecimento dos próprios estados psíquicos; já em relação a outras pessoas, tem-se conhecimento de suas manifestações e ações perceptíveis, mas não de seus estados psíquicos. Que outros homens tenham uma consciência, isso é uma inferência tirada a partir de sua semelhança conosco, portanto, uma inferência per analogiam. Essa inferência espontânea, que torna compreensível o comportamento perceptível do outro, esteve presente nas projeções animistas e em construções derivadas delas; no entanto, o espírito moderno já lhe questiona a validade em relação à totalidade do mundo, ao inanimado, às plantas e até mesmo aos animais, conservando-a apenas no tocante ao outro humano, cuja semelhança com o eu é grande. Mesmo nesse caso, porém, nunca se chega a adquirir a mesma certeza que alguém possui quanto à própria consciência (Freud, 1915c/1975).

Ora, na suposição do inconsciente, a Psicanálise não reivindica outra coisa senão que o indivíduo volte esse habitual procedimento de inferência a si próprio: julgando todos os atos e manifestações que em si nota e que não sabe conectar com o restante de sua vida psíquica como se remontassem à atividade anímica de um outro imperceptível. Entretanto, isso não deve conduzir à suposição de uma segunda consciência em cada homem, unificada à que lhe é diretamente co- 
nhecida; pois, basicamente, uma consciência da qual o portador nada sabe é diferente de uma alheia, e é questionável se uma consciência à qual falta a característica mais importante pode ser considerada uma consciência (Freud, 1915c/1975). A inferência dirigida à própria pessoa culmina na suposição da existência não de uma segunda pessoa ou consciência em cada indivíduo, mas de uma atividade psíquica diferente da consciente, identificada a um ser impessoal e batizada posteriormente com o sugestivo "isso" (Es) (Freud, 1923/ 1975).

$\mathrm{O}$ argumento aduzido em favor da legitimidade da suposição em questão revela o caráter não empírico do objeto da investigação psicanalítica e o problema envolvido em sua admissão. $O$ inconsciente revela-se como algo de natureza psíquica que é em si mesmo inconsciente e que, assim, não se confunde com o que nos aparece ao sentido interno. Por isso, Freud assemelha-o à coisa em si segundo Kant e traça uma analogia entre a correção que o filósofo, com sua crítica, impôs ao espírito no tocante à percepção do mundo e aquela que lhe impôs a Psicanálise em relação à percepção de si próprio: a crítica do conhecimento, refletindo sobre as condições subjetivas de acesso ao exterior, alertou quanto ao erro de se tomar os objetos dos sentidos pelas coisas em si mesmas, cujo conhecimento ultrapassa os limites do entendimento humano. Do mesmo modo, a Psicanálise, ao admitir o inconsciente, exorta a não pôr os eventos psíquicos percebidos no lugar da realidade psíquica, constituída por processos inconscientes. Dada a natureza desses processos, não é possível encontrar para sua existência uma prova direta, por exemplo, ter deles uma percepção e fazer uma experiência de sua atuação sobre o psiquismo consciente; resta uma prova indireta, uma inferência a partir dos fenômenos que supostamente são seus efeitos. Esse procedimento assemelha-se, por sinal, à operação intelectual que se encontra na base do animismo. À semelhança do animismo, a Psicanálise infere a existência de algo imperceptível a partir do perceptível, apenas restringindo esse procedimento ao âmbito psíquico. Enquanto o animismo remonta tanto os eventos externos quanto internos (o ribombar do trovão, o desabrochar das flores, os sonhos e as enfermidades humanas) à ação de espíritos ocultos, a Psicanálise infere a partir de eventos psíquicos conscientes (sintomas, sonhos e lapsos) a existência de uma atividade anímica inconsciente. A suposição do inconsciente é, por um lado, um aprimoramento (Fortbildung) do animismo primitivo, por outro uma continuação (Fortsetzung) da correção kantiana:
A suposição psicanalítica da atividade anímica inconsciente perece-nos, por um lado, uma evolução do animismo primitivo, o qual por toda parte refletiu diante de nós réplicas de nossa consciência e, por outro, a continuação da correção que fez Kant de nossa concepção da percepção externa. Assim como Kant nos advertiu que não desconsiderássemos o condicionamento subjetivo de nossa percepção e não tomássemos nossa percepção por idêntica ao percebido incognoscível, assim a Psicanálise exorta a não se pôr a percepção da consciência no lugar do processo psíquico inconsciente, que é o seu objeto. Assim como o físico, o psíquico também não precisa ser na realidade tal como nos aparece. Preparamosnos, porém, com satisfação para a experiência de que a correção da percepção interna não oferece tanta dificuldade quanto a da externa, que o objeto interno é menos incognoscível [minder unerkennbar] que o mundo exterior (Freud, 1915c/1975, pp.129$130)^{2}$

Pelo modo como é concebido, o inconsciente extrapola os limites da capacidade humana de conhecimento, assemelhando-se por isso à coisa em si. Que Freud, ciente disso, ainda procure justificá-lo, isso só revela a coragem em não recuar diante desse objeto e o desejo de ganhá-lo à ciência. Movido pela "vontade de ciência", o psicanalista nutre a expectativa de que o incognoscível possa ser "menos incognoscível"; que a impossibilidade possua graus.

\section{A Necessidade da Suposição do Inconsciente}

A demonstração da necessidade da suposição do inconsciente tem importância decisiva porque é a partir dela que se arrisca uma prova da existência do inconsciente. Uma prova semelhante já havia sido tentada no já mencionado Algumas notas sobre o conceito de inconsciente na Psicanálise (1912/1975). Na ocasião, procurou-se inferir a necessidade da suposição e a existência do inconsciente a partir principalmente de fenômenos psíquicos não pertencentes exclusivamente ao campo da investigação psicanalítica, um dos quais bem corriqueiro: uma representação ou qualquer outro elemento psíquico pode agora estar presente em minha consciência e no momento seguinte desaparecer dela; após um tempo ela emerge completamente inalterada como lembrança, sem que resulte de uma nova percepção sensível. Para se esclarecer esse fato, é-se forçado à suposição de que a representação relembrada também esteve presente no espírito durante esse ínterim, só que em estado inconsciente (Freud, 1912/1975). 
O outro fenômeno foi produzido num experimento conduzido por Bernheim, no qual uma pessoa é colocada num estado hipnótico e daí despertada. Enquanto, sob a sugestão do médico, ela se encontrava naquele estado, foi-lhe requerido cometer uma ação num momento determinado. Após o hipnotizado ter recobrado a consciência e a habitual constituição anímica, mesmo não tendo qualquer recordação do estado hipnótico, impôs-se a ele o impulso de fazer aquilo no momento anteriormente estipulado, e a ação foi realizada mesmo sem o onhecimento de seus motivos. Os resultados desse experimento levam à conclusão de que a sugestão do hipnotizador e a resolução de executar a ação determinaram inconscientemente o comportamento daquela pessoa (Freud, 1912/1975).

Sob a consideração de ambos os fenômenos seríamos forçados à suposição da existência do inconsciente? Ocorre que essas inferências, também mencionadas no artigo de 1915, podem ser objetadas pelo mencionado opositor da tese psicanalítica, que afirma não haver necessidade alguma nelas; partindo dos mesmos fenômenos, este infere, por exemplo, a existência não de representações inconscientes, mas de uma disposição física ou um resto de processos somáticos a partir do qual o psíquico pode novamente produzir-se. Freud reputa a objeção falha por pressupor a equivalência entre o consciente e o psíquico quando se trataria justamente de demonstrá-la, e por relegar à fisiologia um dos fenômenos mais familiares à psicologia: a memória (Freud, 1912/1975). Contudo, mesmo nutrindo reservas a essas objeções, Freud parece ser sensível a elas. Tenta ainda outra demonstração.

Os dados da consciência são em alto grau lacunares. A análise nos coloca a par de certos atos psíquicos que ocorrem a despeito ou contra a deliberação consciente, como sintomas psíquicos e fenômenos compulsivos; também a vivência cotidiana nos familiariza com atos desse tipo: sonhos, atos falhos, associações inusitadas e resultados de pensamento cujo processo de elaboração nos resta velado. Eles permanecem desconexos (zusammenhanglos) e incompreensíveis (unverständlich) se nos aferramos à pretensão de que deva ser consciente tudo o que se passa em nossa vida anímica, mas ordenam-se numa conexão demonstrável se neles interpolamos atos inconscientes. Ora, caso não se tenha interesse em entender tais atos disruptivos, então não há necessidade alguma de admitir a existência de uma atividade psíquica inconsciente; se, ao contrário, nutrimos interesse teórico em relação ao psiquismo, então o ganho em sentido e conexão proporcionado pela suposição é um motivo inteiramente justificado que permite levar-nos "para além da experiência imediata" (über die unmittelbare Erfahrung hinaus) (Freud, 1915c/1975, p.126). Ainda mais: se nutrirmos tal interesse, então não apenas é possível, mas necessário que aceitemos a suposição, pois esta é a única capaz de satisfazê-lo: caso se admita que as supostas recordações e intenções que escapam ao campo de nossa consciência correspondem na verdade a resíduos de processos somáticos, veremos que ela em nada ilumina esses fenômenos como também gera consequiências indesejáveis. A principal consiste no comprometimento com o paralelismo psicofísico e as embaraçosas dificuldades que ele suscita: como se estabelece a correspondência entre um processo somático e um evento psíquico? Como pode esse último, ao deixar a consciência, conservar-se na forma residual de processo somático e recobrar ulteriormente expressão psíquica? (Freud, 1915c/1975).

$\mathrm{O}$ argumento em favor da necessidade da suposição do inconsciente pode, enfim, ser reconstituído da seguinte maneira: (1) se há interesse em conferir inteligibilidade aos eventos psíquicos, e se (2) há certos eventos que só podem ser compreendidos com a suposição de atos inconscientes, então (3) deve-se supor a existência do inconsciente.

A demonstração da necessidade da suposição passa, em seguida, à prova da própria existência do inconsciente: se, ao supormos a existência disso, conseguimos estruturar um agir bem-sucedido, por meio do qual podemos influenciar os processos conscientes conforme os fins práticos da análise, então é porque o inconsciente existe (Freud, 1915c/1975). Freud vê na eficácia da suposição uma prova suficiente da existência do suposto.

\section{Exame Geral da Justificação}

Um exame atento mostra que os argumentos freudianos não justificam a suposição do inconsciente a partir da indicação direta à experiência, mas da utilidade das conseqüências acarretadas por essa suposição. Tal procedimento foi identificado, aliás, por Symanke e Caropreso em seu trabalho sobre a Justificação (2008). Contudo, o que esses autores chamam de "justificação pragmática" é, a seu ver, apenas o desdobramento de uma demonstração empírica e não o próprio cerne, inassimilável ao modelo empírico, da argumentação freudiana. $\mathrm{O}$ reconhecimento do papel estruturante desse procedimento na justificação do inconsciente leva-nos, antes, a compreendê-la em seu todo como uma demonstração pragmática. 
Com efeito, a suposição em apreço é necessária porque, admitindo-a, são explicados fenômenos psíquicos de outro modo incompreensíveis; em contrapartida, a suposição de equivalência entre consciência e psiquismo deve ser rejeitada porque leva a remontar tais fenômenos ao somático, o que em pouco contribui ao seu esclarecimento. As conseqüências da admissão da primeira suposição coincidem com a obtenção de um determinado interesse. Ela é, portanto, conforme a fim (zweckmäßig), enquanto a segunda, no que traz consequências indesejáveis, não é conforme a fim (unzweckmäßig) (Freud, 1915c/1975). A prova da existência do inconsciente tem a mesma estrutura argumentativa. A ela se dá adesão porque, supondo-se o inconsciente, consegue-se estruturar uma ação capaz de produzir efeitos sobre o curso psíquico convenientemente (zweckdienlich) aos fins práticos da análise.

Também a legitimidade da suposição é assim reivindicada, embora de modo indireto. É certo que a inferência de uma atividade psíquica despercebida a partir de certos fenômenos psíquicos é análoga à inferência da consciência de outrem a partir dos seus atos perceptíveis a nós. Mas o argumento ganha força ao fazer apelo às conseqüências indesejáveis geradas pela eventual rejeição da suposição do inconsciente. Se um objetor, insatisfeito com o caráter incerto do procedimento de analogia, negasse legitimidade a essa suposição, então haveria de rejeitar pela mesma razão a suposição de uma consciência alheia, o que dificilmente faria, já que esta, mais espontânea e habitual do que a do inconsciente, sustenta a maioria das práticas humanas.

Como foi dito, Freud busca conformar a admissão do inconsciente ao modelo de formação dos conceitos científicos, o que será alcançado sob a condição de se demonstrar sua existência - ou ao menos o direito de supô-la - através da indicação das relações entre a ideia de inconsciente e o material empírico. De fato, a demonstração pragmática do inconsciente sempre apela de alguma forma aos fenômenos (sonhos, sintomas psíquicos, efeitos terapêuticos, etc.); mas sempre há algo de insuficiente nela.

Ainda que legitimada pelo hábito, a inferência analógica do inconsciente a partir de fenômenos psíqui$\cos$ desruptivos não rende qualquer certeza a respeito de sua existência, uma vez que não se pode atestá-la no momento de sua atuação. Resta sempre em aberto se outros fatores causaram tais fenômenos.

Já o argumento pela necessidade da suposição não tem a força esperada porque uma das premissas se refere não a um fato, mas ao interesse de conhecer, o qual não se impõe necessariamente ao espírito, é opcional. Ademais, os fenômenos disruptivos mencionados em apoio à admissão do inconsciente parecem já pressupô-la em sua descrição. A quem não se inclina à suposição do inconsciente, atos falhos parecem ser erros fortuitos, sintomas psíquicos, meras disfunções, e sonhos, fenômenos aleatórios.

Por sua vez, é insatisfatório basear a prova da existência do inconsciente na eficácia terapêutica de sua suposição porque ações igualmente eficazes podem ser produzidas com a admissão de suposições diferentes. O exorcista, ao admitir a existência de espíritos malignos, também opera modificações sobre alguém que acredita estar possuído; o xamã da tribo Cuna conduz com sucesso um parto complicado crendo que o deus Muu roubou da parturiente o seu duplo espiritual e que é preciso restituí-lo à proprietária (Lévi-Strauss, 1967). Se a eficácia da suposição for critério suficiente para a admissão da existência do suposto, então por que deveríamos admitir, em face de tantas suposições eficazes, apenas a existência do inconsciente?

$\mathrm{Na}$ verdade, os argumentos aduzidos na justificação do inconsciente revelam que sua admissão, antes que derivada dos fenômenos, é uma condição para a descrição e elaboração, até mesmo para a produção de fenômenos. Até aí nada que se desvie muito da concepção de método científico aceita por Freud, segundo a qual a experiência, o acesso às coisas mediante os sentidos, é um ato orientado segundo princípios ou conexões não empíricas. O que por fim empresta à teoria dos processos psíquicos inconscientes caráter especulativo é o fato de versar sobre um objeto concebido como estando além de toda e qualquer percepção, um objeto inverificável. É por isso que o aparato demonstrativo mobilizado para se justificar a admissão desse objeto nunca provê certeza; quando muito persuade a tornar a disciplina recém-criada menos absurda aos indiferentes ou refratários. O procedimento da Justificação mostra-se, por sinal, análogo ao de uma célebre argumentação forjada dois séculos antes em favor da existência de Deus, a aposta de Pascal.

\section{A Aposta de Pascal}

Não é difícil observar pontos em comum entre a estrutura argumentativa forjada por Freud na Justificação e a prova de Pascal, em que pese o longo tempo que separa suas formulações. Primeiramente, contexto da obra pascalina: o século XVII na Europa é uma época em que fortes correntes de espiritualidade con- 
vivem com o esforço de revisão crítica em todos os domínios do pensamento a partir da nova importância atribuída à experiência e ao experimentalismo como método científico. Sensível às perspectivas imensas oferecidas pela razão experimental à investigação no domínio das ciências exatas, ele próprio, um cientista de vanguarda e incansável experimentador, Pascal ainda assim resistiu à mentalidade que vinha a reboque das inovações, mentalidade orgulhosa de sobrevalorização, quase de endeusamento da razão. Mantendo-se inabalável em suas convicções, foi uma voz desenganada no raiar do racionalismo moderno, anunciando a estreiteza e a fragilidade do intelecto humano (Chevalier, 1936).

O conjunto de fragmentos onde se encontra a mencionada prova, reunidos pela tradição na obra conhecida como Os pensamentos de Pascal, destinava-se a integrar uma apologia da religião cristã. Seu fim era mostrar, sobretudo a ateus e indiferentes, que o cristianismo não é nem obscurantista nem arbitrário, e pretendia convencê-los empregando vários métodos, sendo o principal deles voltar contra os oponentes sua arma mais poderosa: "será uma das confusões dos precitos ver que serão condenados por sua própria razão, pela qual pretenderam condenar a religião cristã" (Pascal, 1936, p. 823). No entanto, dada a natureza do que professa essa religião, seria vão tentar uma demonstração lógica ou experimental, pois ela trata de algo que escapa aos limites impostos às coisas pelo pensamento humano: Deus é incompreensível porque, não tendo parte nem limites, não tem qualquer comparação conosco; porém, se uma demonstração racional de sua existência é impossível, isso não significa que não se possa encontrar um argumento razoável para se crer nela. Fundindo, então, um cálculo de jogo a razões que contemplam ao anseio humano por felicidade, Pascal chega ao célebre argumento da aposta.

Aposta é um ajuste entre pessoas que fazem afirmações diferentes sobre um fato que ainda não se conhece bem ou não ocorreu, o qual será averiguado posteriormente. Os apostadores geralmente empenham um bem que perderão caso errem em seus juízos, mas que põem em risco na esperança de ganharem outro em caso de acerto. Tal ajuste envolve, portanto, a afirmação convicta sobre algo não sabido no momento.

Ora, justamente porque o estado atual do homem não o permite decidir contundentemente quanto à existência de Deus, e porque não pode abdicar de fazê-lo dada a exigência de encontrar certezas em sua vida sempre cambiante, é que o filósofo propõe um tal ajuste para resolver a questão. Nesse caso, porém, o que está em jogo não é bem um fato, sua averiguação não será feita nessa vida e é problemático que o seja em outra. Pois bem: Deus existe? Não existe? Cara ou coroa? Se procuramos ganhar a felicidade e evitar a miséria, então devemos, sem hesitar, apostar na primeira opção: se apostamos em Deus, em ganhando, ganhamos tudo - a felicidade eterna - e, em perdendo a aposta, não perdemos nada. Se, ao contrário, apostamos no finito, em ganhando, não ganhamos nada, e, em perdendo, perdemos tudo (Pascal, 1936).

Observa-se que ambos, Pascal e Freud, sem abandonar o terreno da razoabilidade empenham-se pela admissão de algo cuja existência escapa tanto à verificação empírica quanto à dedução lógica. Em ambos, a admissão em questão é reivindicada por serem suas conseqüências afins a certos interesses. A aposta em Deus satisfaz o interesse prático do apostador, pois, caso seja acertada, lhe trará um estado permanente de contentamento, e, caso não o seja, não atentará contra esse interesse; do mesmo modo, a admissão do inconsciente é reclamada porque com ela se satisfaz o interesse teórico de esclarecimento de fenômenos psíquicos de outro modo ininteligíveis e se estrutura uma ação transformadora sobre o seu curso conforme os interesses práticos da análise: diminuição do sofrimento psíquico, mitigação das inibições ou restituição da capacidade de trabalho e amor ${ }^{3}$.

\section{CONSIDERAÇÕES FINAIS}

A Psicanálise, por ter no inconsciente o seu principal objeto, não se deixa tomar simplesmente por uma ciência empírica. A importância da Justificação reside justo no fato de mostrar que o inconsciente, o qual em razão de sua própria definição chega a ser aproximado à coisa em si kantiana, furta-se a toda verificação empírica ou experimental. Ainda que motivada pela busca de conformar a Psicanálise ao modelo epistemológico hegemônico, essa justificação faz recurso a um procedimento demonstrativo bem diverso ao prescrito por tal modelo, a saber, a uma demonstração pragmática, que intenta comprovar a existência do inconsciente a partir dos efeitos de sua suposição.

Isso não significa que a Psicanálise encerre procedimentos absolutamente originais. Demonstração semelhante já havia sido empregada nos quadros do pensamento teológico de Pascal. $\mathrm{Na}$ impossibilidade de uma comprovação empírica ou racional da existência de Deus, o filósofo procurou justificar sua afirmação tratando-a como uma aposta cujo acerto traria 
consequiências infinitamente melhores a seu apostador do que a aposta contrária. No entanto, o fato de a Psicanálise repousar sobre uma suposição semelhante àquela aposta não a condena ao reino da especulação. A "aposta no inconsciente", assim o indica sua justificação, conduz o psicanalista a determinada descrição e compreensão dos fenômenos psíquicos, possibilitando-o até mesmo produzir tais fenômenos através de ação clínica. $O$ inconsciente, de fato, não pode ser percebido; mas não é menos verdadeiro que a ideia de inconsciente, uma vez admitida, torna certas coisas perceptíveis. Munidos dela - e talvez movidos por seu referente incognoscível - analista e analisando assumem uma posição em referência à qual fenômenos lhes vêm ao encontro, conectando-se numa genuína experiência.

Mas por que admitir o inconsciente? Levantar-se-á a objeção de que o argumento freudiano em favor disso aduz uma eficácia de muito mais modesta que a proporcionada pela aposta em Deus; nem de longe a assunção do inconsciente nos premia com a bemaventurança, de modo que sequer nos veríamos impelidos a tomar parte na querela acerca de sua existência. E mesmo que sejamos sensíveis aos benefícios que sua suposição promete, é questionável se ela nolos proporcionaria, caso nos decidíssemos a seu favor. É certo que essa suposição até nos permite iluminar ocorrências obscuras em nossa vida psíquica, mas ela também obscurece o que nos parece perfeitamente claro, como os atos cotidianos que acreditamos realizar movidos por inequívoca intenção. Com essa suposição, é verdade, o analista chega a intervir com algum sucesso sobre o curso de uma neurose, o analisando empreende um trabalho que às vezes o arranca à inércia de sua mórbida satisfação; contudo, a eficácia terapêutica da ação clínica é bastante limitada, e Freud não hesita em confirmá-lo em momentos de menor otimismo (Freud, 1937/1975).

Por ocasião do centenário de Freud declara Gustavo Corção (1956) em tom lamentoso que, após a revolução psicológica impetrada pela Psicanálise, o homem surge mais enigmático do que nunca; já não pode ir e vir inocente e despreocupado, parar numa vitrine, esquecer um encontro ou assobiar, sem que esses gestos lhe insinuem alguma coisa subjacente. Uma vez tendo ousado admitir o inconsciente, seja isso acertado ou não, somos lançados em dolorosas reflexões sobre eventos de nossa vida de outro modo insignificantes, perigamos cair em preocupações e tormentos adicionais. Na ausência de argumentos contundentes também está, pois, a peculiaridade da assunção do inconsciente. É uma decisão algo radical, não amparada suficientemente em razão, cálculo ou experiência. É aposta de tipo estranho, exige o empenho de uma vida e não promete maior ganho.

\section{REFERÊNCIAS}

Assoun, P.-L. (1983). Introdução à epistemologia freudiana (H. Japiassu, Trad.). Rio de Janeiro: Imago.

Assoun, P.-L. (1996). Metapsicologia freudiana: uma introdução (D. D. Estrada, Trad). Rio de Janeiro: Zahar.

Bernard, C. (1966). Introduction à l'étude de la Médicine Experimentale. Paris: Garnier Flammarion. (Original publicado em 1865)

Birman, J. (1994). Psicanálise, ciência e cultura. Rio de Janeiro: Zahar.

Cavé, M (1945). L'ouvre paradoxale de Freud. Paris: PUF.

Dalbiez, R. (1947). O método psicanalítico e a doutrina de Freud: Vols. I e II (J. L. Lopes, Trad.). Rio de Janeiro: Agir.

Caropreso, F., \& Simanke, R. T. (2008) Uma reconstituição da estratégia freudiana para a justificação do inconsciente. Agora, vol. XI, n.1, pp. 31-51.

Chevalier, J. (1935) Préface. Em J. Chevalier (Org.), L'ouvre de Pascal (pp. 7-13). Paris: Pleiade.

Corção, G. (1956, 20 de maio). O Centenário de Freud. Diário de Notícias. Retirado de http://permanencia.org.br/drupal/node/313 em 01 de setembro de 2012

Freud, S. (1974) O inconsciente. Em J. Strachey (Org.), Edição standard das obras psicológicas completas de Sigmund Freud (vol. 14, pp. 183-245). Rio de Janeiro: Imago.

Freud, S. (1975). Einige Bemerkungen über den Begriff von Unbewußte in der Psychoanalyse. In A. Mitscherlich, A. Richards \& J. Strachey (Orgs.), Die Freud-Studienausgabe (Vol.3, pp.29-36). Frankfurt am Main: Fischer. (Original publicado em 1912)

Freud, S. (1975). Triebe und Triebschiksale. In A. Mitscherlich, A. Richards \& J. Strachey (Orgs.), Die Freud-Studienausgabe (Vol.3, pp.81-102). Frankfurt am Main: Fischer. (Original publicado em 1915a)

Freud, S. (1975). Die Verdrängung. In A. Mitscherlich, A. Richards \& J. Strachey (Orgs.) Die Freud-Studienausgabe (Vol. 3, pp. 107-118). Frankfurt am Main: Fischer. (Original publicado em 1915b)

Freud, S. (1975). Das Unbewußte. In A. Mitscherlich, A. Richards \& J. Strachey (Orgs.), Die Freud-Studienausgabe (Vol. 3, pp. 125-173). Frankfurt am Main: Fischer. (Original publicado em 1915c)

Freud, S. (1975). Metapsychologische Ergänzung zur Traumlehre. In A. Mitscherlich, A. Richards \& J. Strachey (Orgs.), Die 
Freud-Studienausgabe (Vol. 3, pp. 125-173). Frankfurt am Main: Fischer. (Original publicado em 1915)

Freud, S. (1975). Das Ich und das Es. In A. Mitscherlich, A. Richards \& J. Strachey (Orgs.), Die Freud-Studienausgabe (Vol. 3, pp. 283-330). Frankfurt am Main: Fischer. (Original publicado em 1923)

Freud, S. (1975). Die endliche und die unendliche Analyse. In A. Mitscherlich, A. Richards \& J. Strachey (Orgs.), Die FreudStudienausgabe (Vol. Complementar, pp. 351-392). Frankfurt am Main: Fischer. (Original publicado em 1937)

Freud, S. (1986). Carta de 10 de março de 1898. In J. M. Masson (Org.), A correspondência completa de Sigmund Freud para Wilhelm Fliess (pp.302-303) (V. Ribeiro, Trad.). Rio de Janeiro: Imago.

Freud, S. (1987). Studien über Hysterie. Em A. Freud (Org.), Gesammelte Werke (Vol. 1, pp. 99-251). Frankfurt am Main: Fischer. (Original publicado em 1893).

Freud, S. (1987). Über eine Weltanschauung. In A. Freud (Ed.) Gesammelte Werke (vol. 15, pp. 170-197). Frankfurt am Main: Fischer. (Original publicado em 1933).

Freud, S. (1987). Entwurf einer Psychologie. In A. Freud (Org.), Gesammelte Werke (Vol. Complementar, pp. 375-477). Frankfurt am Main: Fischer. (Original publicado em 1895).

Garcia-Roza. L. (1991). Introdução à Metapsicologia freudiana I, Rio de Janeiro: Zahar.

Gill, M. (1976). Metapsychology is not Psychology. In M. Gill \& P. Holzmann (Orgs.), Psychology versus Metapsychology (pp. 71-105). New York: International Universities.
Holt, R. (1989). The manifest and latent meanings of Metapsychology. In R. Holt, Freud Reappraised (pp. 15-33). New York: The Guilford Press.

Lacan, J. (2008). O Seminário, livro 16: de um outro ao outro (Vera Ribeiro, Trad.). Rio de Janeiro: Jorge Zahar.

Lévi-Strauss, C. (1967). A Eficácia Simbólica. In C. Lévi-Strauss, Antropologia Estrutural. (pp. 215-237) (C. S. Katz \& E. Pires, Trad). Rio de Janeiro: Tempo Brasileiro.

Pascal, B (1936). Pensées. In J. Chevalier (Org.), L'ouvre de Pascal (pp. 815-1095). Paris: Pleiade.

Politzer, G. (1974). Critique des fondements de la Psychologie $\left(4^{\mathrm{a}}\right.$ ed.). Paris: PUF. (Original publicado em 1928).

Wakefield, J. C. (1992) Freud and cognitive psychology: the conceptual interface. In J. Barron; J. Eagle; M. N. \& D. L. Wolitzky. (Orgs.), Interface of psychoanalysis and psychology (pp. 77-98). Washington: American Psychological Association.

Recebido em: 15/09/2012

Primeira Decisão Editorial em: 09/03/2013

Aceito em: 20/03/2013

Notas:

1 Não parece nada fortuito o erro cometido pela Imago na tradução do título da seção. O original "Die Rechtfertigung des Unbewußten" (A justificação do inconsciente) foi equivocadamente traduzido para o português como "Justificação do conceito de inconsciente" (Freud, 1974, p.183). O erro é provavelmente motivado pela intrínseca relação mantida, na demonstração freudiana, entre conceito e existência do inconsciente.

2 Tradução nossa.

3 A referência à aposta de Pascal não é inédita no campo psicanalítico. Jaques Lacan também foi levado a ela, mas através de outras vias. Com efeito, o psicanalista francês não relaciona diretamente a célebre aposta nem com o argumento desenvolvido na seção primeira de $O$ inconsciente, nem, de modo geral, com a questão freudiana acerca da existência do inconsciente. A esse respeito, ver $S e$ minário 16: de um outro ao outro (Lacan, 2008). 